\title{
Prevalence and distribution of high-risk human papilloma virus (HPV) types in invasive squamous cell carcinoma of the cervix and in normal women in Andhra Pradesh, India
}

\author{
A Pavani Sowjanya1, Meenkashi Jain ${ }^{2}$, Usha Rani Poli ${ }^{3}$, S Padma1, \\ Manik Das ${ }^{2}$, Keerti V Shah ${ }^{4}$, BN Rao ${ }^{3}$, Radha Rama Devi ${ }^{1}$, Patti E Gravitt ${ }^{4}$ and \\ Gayatri Ramakrishna*1
}

Address: ${ }^{1}$ Centre for DNA Fingerprinting and Diagnostics, Hyderabad, A.P, India, ${ }^{2}$ Mediciti Rural Hospital, Medchal Mandal, A.P., India, ${ }^{3}$ M.N.J. Regional Cancer Hospital, Hyderabad, A.P., India and ${ }^{4}$ Johns Hopkins University, Baltimore, USA

Email: A Pavani Sowjanya - pavani@cdfd.org.in; Meenkashi Jain - docmeena@rediffmail.com; Usha Rani Poli - usharani@eth.net; S Padma - padma@cdfd.org.in; Manik Das - das@yahoo.com; Keerti V Shah - kvshah@jhsph.edu; BN Rao - bachina_n_rao@yahoo.com; Radha Rama Devi - radha@cdfd.org.in; Patti E Gravitt - pgravitt@jhsph.edu; Gayatri Ramakrishna* - gayatri@cdfd.org.in

* Corresponding author

Published: 22 December 2005

BMC Infectious Diseases 2005, 5:116 doi:10.1186/1471-2334-5-116

This article is available from: http://www.biomedcentral.com/I47I-2334/5/II6

(C) 2005 pavani Sowjanya et al; licensee BioMed Central Ltd.

This is an Open Access article distributed under the terms of the Creative Commons Attribution License (http://creativecommons.org/licenses/by/2.0), which permits unrestricted use, distribution, and reproduction in any medium, provided the original work is properly cited.
Received: 17 June 2005

Accepted: 22 December 2005

\begin{abstract}
Background: Despite the high incidence of cervical cancer reported from India, large scale population based studies on the HPV prevalence and genotype distribution are very few from this region. In view of the clinical trials for HPV vaccine taking place in India, it is of utmost importance to understand the prevalence of HPV genotypes in various geographical regions of India. We investigated the genotype distribution of high-risk HPV types in squamous cell carcinomas and the prevalence of high-risk HPV in cervicovaginal samples in the southern state of Andhra Pradesh (AP), India.
\end{abstract}

Methods: HPV genotyping was done in cervical cancer specimens $(n=4 I)$ obtained from women attending a regional cancer hospital in Hyderabad. HPV-DNA testing was also done in cervicovaginal samples $(n=185)$ collected from women enrolled in the cervical cancer screening pilot study conducted in the rural community, of Medchal Mandal, twenty kilometers away from Hyderabad.

Results: High-risk HPV types were found in $87.8 \%(n=36 / 4 I)$ of the squamous cell carcinomas using a PCR-based line blot assay. Among the HPV positive cancers, the overall type distribution of the major high-risk HPV types was as follows: HPV 16 (66.7\%), HPV 18 (19.4\%), HPV 33 (5.6\%), HPV 35 (5.6\%), HPV 45 (5.6\%), HPV 52 (2.8\%), HPV 58(2.8\%), HPV $59(2.8 \%)$ and HPV 73 (2.8\%). Women participating in the community screening programme provided both a self-collected vaginal swab and a clinician-collected cervical swab for HPV DNA testing. Primary screening for high risk HPV was performed using the Digene Hybrid Capture 2 (hc2) assay. All hc2 positive samples by any one method of collection were further analyzed using the Roche PCR-based line blot for genotype determination. The prevalence of high risk HPV infection in this community-based screening population was $10.3 \%$ (19/185) using the clinician-collected and $7.0 \%$ ( $13 /$ 185) using the self-collected samples. The overall agreement between self-collected and clinician-collected samples was 92\%; however among HPV-positive specimens, the HPV agreement was only moderate (39.1\%). The most frequently detected HPV types in the Medchal community are HPV 52 and 16.

Conclusion: Our results suggest that the HPV type distribution in both cervical cancer tissues and in a general screening population from Andhra Pradesh is similar to that reported in India and other parts of the world. We also conclude that an effective vaccine targeting HPV 16 will reduce the cervical cancer burden in AP. 


\section{Background}

Cervical cancer is one of the most common malignancies and is the major cause of cancer mortality among Indian women. [1,2]. Cytology screening (e.g., Pap test) is the standard method used for the control of cervical cancer in India, however organized screening programs are rare. Despite the availability of Pap testing even on an opportunistic basis in India, the incidence of invasive cervical cancer remains high, especially in rural India [3-5]. The failure of cytological testing in rural India is likely due to a number of factors which include (a) poor infrastructure, (b) lack of trained health professionals and cytotechnicians, (c) absence of organized community based screening programs and (d) inadequate follow-up of abnormal smears [6].

In the past decade, a strong etiologic association between infection with high-risk HPV types and development of cervical cancer has been established, and vaccines targeting HPV 16 and 18 have been shown to prevent persistent HPV infections in clinical trials $[7,8]$. Mass immunization with these vaccines has the potential of greatly reducing the cervical cancer incidence in India and elsewhere, though the efficacy of the current vaccine formulations is type-specific, and will only prevent infection with the few types available in the vaccine cocktail. The spectrum of HPV types targeted in current vaccine trials is based largely on the prevalence of HPV types in cancers from the developed world. Because geographical variation in type distributions may exist, knowledge about the distribution of HPV types in cervical cancers and HPV types circulating in the communities in different regions of India would be useful in devising the optimum strategy for vaccination in India [9-11].

Most studies in India have only assessed the prevalence of HPV 16 and 18 in cervical cancer tissues. In spite of the fact that cervical cancer burden in India is high, there are very few large scale studies from India describing either HPV prevalence or type distribution in the general population and in invasive cervical cancer $(12,13,14,15)$. Because of subtle regional cultural differences that exist in various states in India, it is important to describe the distribution of HPV genotypes in cancer cases and community samples from multiple representative populations before these data can be generalized for application in national cancer prevention strategies. The present study reports the HPV type distribution in a rural community (20 Km from Hyderabad city) and invasive cancer samples from women attending the regional cancer centre in Hyderabad.

\section{Methods \\ Collection of cancer specimens}

For the cancer study conducted at the $\mathrm{MNJ}$ regional cancer hospital (between 2002-2003), women were consecutively recruited at the time of their visit to the cancer clinic. A tissue biopsy was collected from women clinically diagnosed with cervical cancer and who gave consent $(n=45)$. Following the cervical punch biopsy, a small piece of tissue was sent for histopathology and the rest of the specimen was snap frozen in liquid nitrogen and stored at $70^{\circ} \mathrm{C}$. Out of the total 45 women, DNA was extracted from forty-two histopathologically proven cases of squamous cell carcinomas. Histopathology was not available from the remaining 3 participants. The study protocol was approved by all participating institutional bioethical committees.

\section{Collection of cervical samples in the rural community of Medchal}

A community-based sample of women aged 30 years and above was recruited from a single village in Medchal Mandal during the period July-October 2003. These women were participating in a cervical cancer screening pilot study entitled Community Access to Cervical Health, or CATCH. A total of 657 age-eligible women were recruited to participate. Consent was obtained from women participating in the study who had not undergone hysterectomy and were not pregnant. Of the 489 women who were eligible, $190(38.9 \%)$ consented to participate and were enrolled. Of the 190 women, HPV analysis was done for 185 women. Both self-collected vaginal samples and clinician-collected cervical samples were collected using a Digene sampling brush which was placed into Digene STM collection medium. Samples were stored at $4^{\circ} \mathrm{C}$ for no more than 24 hours. Before aliquoting, the STM tubes are vortexed to dislodge cells and then aliquoted without removing the brush. The aliquoted samples were stored at $-80^{\circ} \mathrm{C}$.

\section{Consent from participant women}

At the MNJ cancer hospital the attending nurse explained the procedure and written consent obtained. For the Medchal community study, the consent was read aloud to the participants as a group. Each eligible participant was then asked privately if they had any questions regarding study participation and written consent was obtained.

\section{HPV-DNA testing by Digene Hybrid capture 2}

The samples collected in the STM tubes were vortexed to dislodge from the brush and $200 \mu$ laliquots from both the self and clinician collected samples were transported to Centre for DNA Fingerprinting and Diagnostics (CDFD) for HPV testing. Aliquotting was done prior to denaturation of the sample for the hc2 test in order to preserve the integrity of the DNA for future PCR analyses. 
Table I: Estimated prevalence of HPV types in squamous cell carcinoma

\begin{tabular}{lcc}
\hline & Number & Percentage total \\
\hline Total sample size & 41 & \\
HPV Negative & 5 & 12.2 \\
HPV Positives & 36 & 87.8 \\
HPV types & & \\
Single Infection & & \\
16 & 21 & 58.3 \\
18 & 6 & 16.7 \\
33 & 1 & 2.8 \\
35 & 2 & 5.6 \\
45 & 2 & 5.6 \\
59 & 1 & 2.8 \\
Multiple infections & & \\
$16 / 58 / 52 / 33$ & 1 & 2.8 \\
$16 / 18$ & 1 & 2.8 \\
$16 / 73$ & 1 & 2.8 \\
\hline
\end{tabular}

Each sample was tested for the presence of one or more high risk HPV types using probe B of the Hybrid Capture 2 (hc2) assay (a pool of full length RNA probes specific for HPV 16, 18, 31, 33, 35, 39, 45, 51, 52, 56, 58, 59, and 68) according to the manufacturer's instructions. The hc2 test is based on the hybridization of HPV DNA with RNA specific probes and they hybrid detected by a chemiluminescent assay. The values obtained are recorded as relative light unit (RLU) per positive control (PC). The sample is considered positive for HPV-DNA when the RLU/PC ratio is greater than or equal to one.

\section{HPV-DNA testing by the Roche PCR Line blot assay}

HPV genotyping was performed on all cervical cancer tissues and on cervicovaginal samples which were hc2 positive by either collection method. The PCR and line blot reagents were kindly provided by Roche Molecular Systems, Inc. The cervical punch biopsy (approximately 50 $\mathrm{mg}$ ) was pulverized using liquid nitrogen, suspended in $1000 \mu \mathrm{l}$ of digestion buffer $(10 \mathrm{mM} \mathrm{NaCl}, 10 \mathrm{mM}$ Tris-Cl pH 8, $25 \mathrm{mM}$ EDTA, $0.5 \%$ SDS and $0.1 \mathrm{mg} / \mathrm{ml}$ proteinase $\mathrm{K})$, extracted using standard phenol:chloroform methods [16], and resuspended in $100 \mathrm{ul}$ of TE buffer. DNA was extracted from the cervical samples collected from the women enrolled in CATCH study by taking $70 \mu \mathrm{l}$ of the STM sample and digesting at $65^{\circ} \mathrm{C}$ in digestion buffer $(20$ $\mathrm{mM}$ Tris-HCl, $1 \mathrm{mM}$ EDTA pH 8.5) containing $200 \mu \mathrm{g} / \mathrm{ml}$ proteinase $\mathrm{K}$ and $0.1 \%$ of Tween 20 for 1 hour. Following heat inactivation of the proteinase $\mathrm{K}\left(95^{\circ} \mathrm{C}\right.$ for $10 \mathrm{~min}-$ utes), the DNA sample was precipitated with ethanol and ammonium acetate. The precipitated DNA was suspended in a final volume of $35 \mu \mathrm{l} \mathrm{TE} \mathrm{buffer.} \mathrm{For} \mathrm{PCR,} 5 \mu \mathrm{l}$ of the DNA sample is amplified using a cocktail of the biotinylated PGMY 09/11 and beta-globin primers in a final volume of $100 \mu \mathrm{l}$. The PCR product is denatured in $0.4 \mathrm{~N}$
$\mathrm{NaOH}$, and subjected to HPV genotyping by the prototype PCR-Line blot assay as described earlier $(17,18)$.

\section{Statistical analysis}

Agreement between self- and clinician-collected samples was calculated using kappa statistics to provide estimates beyond chance agreement. To test for differences in HPV prevalence by age, we calculated Pearson's chi-square. Results were considered statistically significant at $\mathrm{p}<0.05$. All frequencies, kappa estimates, and chi-square tests were computed using Stata/SE version 9.0 (Stata Corp., College Station, TX).

\section{Results \\ Prevalence and distribution of HPV types in cervical cancer tissues}

A total of 42 specimens were tested. The age range of the women was 30 to 65 years with a median age of 55 years. The majority of women attending MNJ for cancer diagnosis and treatment are of low socioeconomic status (average income 1000-1500 Rs per month) based on data from hospital records. However, specific details regarding the socioeconomoic or demographic status were not collected from individual women participating in the invasive cancer study. HPV genotyping of the samples was done using the line blot assay and of the total 42 samples tested, one was negative for beta-globin and was excluded from further analyses. Of the 41 tissues with satisfactory $\beta$ globin amplification, $36(87 \%)$ were HPV positive. Among the 36 HPV positive tissues, HPV 16 was the most prevalent type detected $(24 / 36,66.7 \%)$, followed by HPV 18 (7/36 19.4\%). Three of the HPV16 positive specimens were co-infected with other HPV genotypes (see Table 1). The remaining tumors were positive for the following HPV types: HPV 33 (2/36, 5.6\%), 35 (2/36, 5.6\%), 45 (2/ $36,5.6 \%), 52(1 / 36,2.8 \%), 58(1 / 36,2.8 \%), 59(1 / 36$, $2.8 \%)$ and $73(1 / 36,2.8 \%)$.

\section{Prevalence and distribution of HPV types in community samples}

For the CATCH pilot study a total of 657 age-eligible women were recruited to participate. Of the 489 women who were eligible, 190 (38.9\%) consented to participate and were enrolled. Women aged $30-45$ were twice as likely to participate $(60.4 \%)$ relative to the next age group $(45-55 ; 29.8 \%$ enrolled). Of the 190 women, HPV analysis was done for 185 women. The median household income reported by the women in the community study was 1500 Rs, which is similar to the general characteristics of the population served at the regional cancer hospital.

Of the 190 women enrolled, 185 had samples collected for HPV testing. HPV genotyping was done in women who tested hc2 positive in either the self- or the cliniciancollected sample. Approximately 10.3\% (19/185) of clini- 
Table 2: HPV-DNA prevalence in women belonging to different age strata in Medchal community

\begin{tabular}{llll}
\hline Age group & $\begin{array}{l}\text { Sample } \\
\text { size }\end{array}$ & $\begin{array}{l}\text { HPV Positive } \\
\text { samples* }\end{array}$ & $\begin{array}{l}\% \text { HPV } \\
\text { positivity }\end{array}$ \\
\hline $30-35$ & 48 & 6 & 13 \\
$36-40$ & 49 & 5 & 10 \\
$41-45$ & 36 & 2 & 6 \\
46 and above & 53 & 6 & 11 \\
& 186 & 19 & 10 \\
\hline
\end{tabular}

* This data represents the clinician-collected samples tested by hc2 assay; Pearson's chi-square $p=0.72$.

cian-collected cervical samples tested positive for highrisk HPV types by the hc2 assay. The HPV prevalence was similar across age strata ( $\mathrm{p}=0.72$, Table 2$)$. All hc2-positive samples were genotyped using the PGMY PCR line blot analysis. One cervical sample was negative for the $\beta$ globin control, leaving a total of 18 of the hc2-positive cervical samples for genotype analysis. By PCR analysis, $13 / 18(72 \%)$ of the hc2-positive cervical samples were confirmed as high risk HPV positive. The genotype distribution among these women with predominately normal cervical cytology is summarized in Table 3. Multiple genotype infections were detected in 2/13 HPV positive women $(15 \%)$, resulting in a total of $17 \mathrm{HPV}$ infections among 13 women. In general, HPV 52 was the most common type detected (5/17 infections, 29.4\%), followed by HPV 16 (17.6\%), HPV 58 (11.7\%), and HPV 33 (11.7\%). HPVs $62,59,39,18$, and 84 were each detected once in the cervical swabs.

We also tested the paired self-collected swabs from each woman in the community-based study using hc2, followed by genotyping of all HPV positive samples using the PCR line blot assay. Approximately 7.02\% (13/185) of the self-collected vaginal swabs were positive for high-risk HPV using the hc2 assay. When tested by PCR, two of the vaginal swabs failed to amplify the $\beta$-globin control, leaving a total of 11 hc2-positive self-collected samples available for analysis. Of these, 7 (64\%) were confirmed as high-risk HPV positive samples, two of which were positive for multiple HPV genotypes resulting in total of 11 infections. HPV 16 and 52 were each present in 2 of the 11 infections (18\%), and HPVs 18, 31, 39, 58, 62, 81, and 84 detected once.

Of the five hc2-positive samples in the clinician-collected set that were not confirmed as positive by PCR, three had $\mathrm{RLU} / \mathrm{PC}$ value ratios between 1.38 and 2.26, while the remaining two had somewhat higher RLU/PC ratios of 4.5 and 14.38. All four hc2-positive self-collected samples

Table 3: Comparison of RLU/PC cutoff values for cervicovaginal samples positive by any one method of collection and genotyping of hc2 positive samples using the PCR based line blot assay

\begin{tabular}{|c|c|c|c|c|}
\hline Sample & $\begin{array}{l}\text { RLU/Co-Clinician } \\
\text { collected }\end{array}$ & $\begin{array}{l}\text { RLU/Co self Self } \\
\text { Collected }\end{array}$ & $\begin{array}{l}\text { HPV type Clinician } \\
\text { collected }\end{array}$ & HPV type Self collected \\
\hline I & 204.27 & 30.8 & 16 & 16 \\
\hline 2 & 179.86 & 0.3 & 52 & - \\
\hline 3 & 151.97 & 0.7 & $52,58,62$ & 58,62 \\
\hline 4 & 78 & 0.2 & 59 & - \\
\hline 5 & 55 & 0.2 & 52 & $-* *$ \\
\hline 6 & 47.33 & 1.6 & 39 & 39 \\
\hline 7 & 35.74 & 5.6 & 52 & 52 \\
\hline 8 & 14.58 & 3.9 & - & - \\
\hline 9 & 11.35 & 398.8 & 18 & $|6| 8,,3|, 8|$ \\
\hline 10 & 1.86 & 0.2 & $16,33,84$ & - \\
\hline II & 9.44 & $2.9(2.95)$ & 58 & 58 \\
\hline 12 & 7.02 & 3.1 & 52 & 52 \\
\hline 13 & 5.69 & 6.2 & $*$ & $*$ \\
\hline 14 & 4.5 & 0.2 & - & - \\
\hline 15 & 3.81 & 1.0 & 33 & - \\
\hline 16 & 2.26 & 0.2 & - & - \\
\hline 17 & 1.51 & 0.2 & - & - \\
\hline 18 & 1.38 & 0.3 & - & - \\
\hline 19 & I.I & 0.6 & 16 & - \\
\hline 20 & 0.19 & 1.2 & - & - \\
\hline 21 & 0.66 & 10.2 & - & 62,84 \\
\hline 22 & 0.97 & 17.4 & - & $*$ \\
\hline 23 & 0.19 & 1.2 & - & - \\
\hline
\end{tabular}

The Rlu/cut-off values are arranged in the descending order for the clinician-collected sample. Values above I.0 is considered positive for HPV and represented in bold.

- HPV negative; * beta globin negative, ** positive for low risk HPV type 
Table 4: Agreement for HPV positivity in cervicovaginal samples by the two methods of collection

\begin{tabular}{|c|c|c|c|}
\hline \multirow[b]{2}{*}{ Clinician collected } & \multicolumn{2}{|c|}{ Self-Collected samples } & \multirow[t]{2}{*}{ Tota } \\
\hline & Positive & Negative & \\
\hline Positive & 9 & 10 & 19 \\
\hline Negative & 4 & 162 & 166 \\
\hline Total & 13 & 172 & 185 \\
\hline
\end{tabular}

Total agreement: $92.4 \%$ (I7I//85); HPV positivity agreement: $39.1 \%$ $(9 / 23) ;$ Kappa $=0.52 ; \mathrm{C} . \mathrm{I}=0.38-0.66$

that were PCR negative had RLU/cutoff ratios ranging from 1.17-3.91. One of the self-collected samples although negative by the hc2 assay showed the presence of oncogenic HPV type 52 on line blot analysis.

The overall agreement of the hc2 results between the two sampling methods was good (92.4\%, Table 4$)$. However, the percentage agreement among the HPV positive samples was only moderate (39\%). A pairwise comparison of the data on the relative light unit/cutoff (RLU/Co) for the 23 samples testing positive for HPV by any one of the collection methods together with the HPV types is shown in Table 3.

\section{Discussion}

The development of HPV vaccines holds tremendous promise for developing countries like India where cervical cancer is the most common malignancy among middleaged women, particularly in the rural areas [3]. The availability of an HPV vaccine will not only help in curbing the cervical cancer incidence and mortality, but may also bring down the cost burden for cervical cancer screening programmes. Already there is a possibility for an HPV vaccine trial in India under the auspices of the Indian Council of Medical Research [11]. To maximize the cost-effectiveness of the HPV vaccination programmes in India, it is important to understand the distribution of the major HPV types in various geographical regions.

We therefore evaluated the prevalence and distribution of major HPV types in cervical tissues from histologically proven cervical neoplasia $(\mathrm{N}=42)$ collected from women attending a cancer clinic at the regional cancer hospital in Hyderabad, Andhra Pradesh. High risk HPV prevalence was approximately $87.8 \%$ in our sample of invasive squamous cell carcinomas. In the present study, low risk HPV types were not detected in the carcinomas. A case-control study undertaken in Chennai, southern India, reported HPV prevalence as high as $99.4 \%$ in their invasive cancer samples [12]. Both studies used broad spectrum, consensus PCR methods for the typing of HPV. However, the method used in Chennai amplified an HPV target of 150 bp, whereas our amplification product using the PGMY $09 / 11$ consensus primers is much larger (450 bp). Therefore, DNA degradation in some of the samples in our study could have led to a false-negative result and an underestimation of the HPV prevalence in cervical cancers from AP State. Similar false negative samples using the degenerate primers MY09/11 (also amplifying 450 bp HPV targets) were found relative to the $150 \mathrm{bp}$ amplicon in a large case-series of cervical tumors conducted by the IARC $[19,20]$.

The most prevalent HPV types found in the invasive cervical cancers in Andhra Pradesh were HPV 16 (66.7\%) followed by HPV 18 (19.4\%). The distribution of HPV types found in our study is quite similar to a recent large-scale study reported from India and is also consistent with the most common types found in South-East Asia [12$14,21,22]$. Therefore, we can confirm that a vaccine targeting HPV 16 could eliminate $>50 \%$ of the cervical cancer burden in Andhra Pradesh, as well as South India. More comprehensive genotyping of cervical cancer tissues from North, West, and Northeast India will be needed to justify a single national vaccine strategy for the Indian subcontinent.

While the incidence of cervical cancer is high in the state of Andhra Pradesh, with an age adjusted rate of 10.3 per 10,000 women [23] few data are available which describe the prevalence or distribution of major HPV genotypes in the general population. We are conducting a cervical cancer screening evaluation study in rural AP, which includes HPV testing as a primary screening method. The present paper reports the prevalence and distribution of major HPV types in cervicovaginal samples from the women enrolled from a single village in Medchal Mandal as part of the CATCH pilot study. A broad range of genotypes were detected in this community-based sample, including many of the types found in invasive cancers from the same region, suggesting that the population prevalence and spectrum of HPV infection in rural India is similar to that seen elsewhere in the world and India $[14,24]$.

Our HPV prevalence (10.4\%) is very similar to two large population-based studies of largely cytologically normal women. Sankarnarayanan, et al. reported 10.3\% high risk HPV prevalence as detected using hc2 testing in Osmanabad District in West India [15], and somewhat lower prevalence estimates by hc 2 in a separate multicentric study in Mumbai (6.3\%), Trivandrum $(4.8 \%)$, and two cities in Kolkatta (7.8 and 5.2\%, respectively) [25]. Franceschi et al report similar high risk prevalence from Dindigul District in South India (9.6\%) using consensus primer PCR methods [14]. None of these studies, including ours, found an association of HPV prevalence with age. Our study and 
that of Sankarnarayanan [26] restricted enrollment to women over age 30 years, which may represent the ageassociated plateau found in other reports. However the study from Dindigul District [14] sampled a large number of women under 25 years and found no increase in HPV prevalence among the younger women. The lack of an age association with HPV prevalence in India is yet unexplained.

We evaluated HPV-DNA testing using both clinician- and self-collected samples from each woman. In this pilot study, the initial screening for high risk HPV DNA was done by Hybrid Capture 2 with positive samples tested for HPV genotype using a PCR-based line blot assay. There was a considerable variation in the RLU/PC values for the self and clinician collected samples, however more than half of the discordant samples had viral loads $<10 \mathrm{RLU} /$ PC. Similarly, most hc2-positive samples that were not confirmed by PCR had low viral load suggesting sampling error as a potential source of variability when sample viral loads are near the assay sensitivity threshold. Further, it is possible that the discrepancy between hybrid capture positive and PCR negative samples in samples with RLU/CO less than 5 is because of non-specific binding in the hc2 assay leading to false positive results.

Clinician collected samples (10.3\%) showed a slightly higher HPV prevalence relative to the self collected samples $(7 \%)$ in the pilot study. The good overall agreement is reflective of a large number of HPV negative samples; continued evaluation of HPV testing in this community with a larger sample size will be required to determine the relative performance of self- vs. clinician-collected samples for HPV testing. Self-sampling as a means to monitor HPV infection post-vaccination may prove to be a valuable tool in post-immunization surveillance in India.

The most prevalent HPV genotypes in the general population of Medchal is HPV 52 followed by HPV 16, which differs slightly from that of rural community in Chennai where the major types were HPV 16 and 56. However, screening of larger samples size in Medchal will give a better picture on the distribution of the HPV types.

Our efforts are therefore continuing in the characterization of HPV genotypes prevalent in the rural areas of Andhra Pradesh. The successful completion of our ongoing studies will help in (a) understanding the distribution and prevalence of HPV types in Medchal Mandal community of Andhra Pradesh, (b) feasibility of self collection methods for HPV-DNA testing in India as an alternate to clinician based sampling, and (c) comparing the three different screening modalities (Pap test, VIA, and HPVDNA testing). Furthermore, combining our results with the ongoing IARC study conducted in the Mahabub Nagar district of Andhra Pradesh and the recently completed IARC assisted studies will help in predicting the most costeffective method of cancer cervix screening programmes in India [27]. A comparative evaluation of such different large scale control studies conducted in India will provide newer insights to formulate better ways to meet the future challenges for cervical cancer prevention in India. Finally, establishment of a well-characterized population with regard to the community prevalence of type-specific HPV infection will provide a valuable baseline for monitoring population effectiveness of an HPV vaccine.

\section{Conclusion}

Our results confirm the earlier studies on the role of high risk HPV infection as a major risk factor development of cancer cervix. Further, the distribution of high risk HPV types in Hyderabad is similar to those reported from a recent study conducted in Southern India. The prevalence of HPV-16 in the cancer samples suggests that effective vaccination against HPV 16 can considerably bring down the cancer burden in the southern states of India.

\section{Authors' contributions}

Keerti Shah and Patti Gravitt were responsible for the overall planning and coordination of the Medchal community based study. Usha Rani Poli, Radha Rama Devi, B.N.Rao helped in providing the invasive cancer specimens for the study. Pavani and Padma were involved in the cancer cervix sample collection. Pavani was responsible for HPV-DNA testing on all the samples using line blot and Hybrid capture-II assay. Meenakshi Jain collected all the cervicovaginal samples from women enrolled in the CATCH programme. Manik Das was responsible for biospecimen processing and inventory. Patti Gravitt provided all the expertise involved with the HPV Line blot assay system. Gayatri Ramakrishna was involved in the coordination and setting up of the HPV-DNA testing system at CDFD and together with Patti Gravitt compiled and finalized the manuscript.

\section{Declaration of Competing interests}

The author(s) declare that they have no competing interests. We have received reagents from Roche Molecular Systems. These are the same reagents used in this manuscript.

\section{Acknowledgements}

We thank all the women who participated in the hospital and enrolled in the community-based study. We are grateful to the doctors and the staff of the pathology department M.N.J. regional cancer hospital for providing the histo-pathology reports. We are greatly indebted to Dr. S. E. Hasnain and Dr. P. S. Reddy for the constant support provided during the study. The Line blot strips and reagents provided by Janet Kornegay and Sean Boyle of Roche Molecular Systems, US is highly appreciated. We also thank Proma Paul, Purushotam Reddy, staff nurse, volunteer health workers and the staff at ITG mediciti hospital for providing the assistance at various stages during the conduct of the study. This study was funded by a grant under the joint 
INDO-US collaborative program of Department of Biotechnology, Ministry of Science and Technology, Government of India and the NIH, USA (BT/IN/ US/CRHR/PP/2002).

\section{References}

I. Shanta V, Krishnamurthi S, Gajalakshmi CK, Swaminathan R, Ravichandran K: Epidemiology of cancer of the cervix: global and national perspective. J Indian Med Assoc 2000, 98:49-52.

2. $\mathrm{Pal}$ SK, Mittal B: Improving cancer care in India: prospects and challenges. Asian Pac / Cancer Prev 2004, 5:226-8.

3. Rakesh Chopra : The Indian Scene. Journal of Clinical Oncology 200 I, 19:106s-IIIs.

4. Rajkumar R, Sankaranarayanan R, Esmi A, Jayaraman R, Cherian J, Parkin DM: Leads to cancer control based on cancer patterns in a rural population in South India. Cancer Causes Control 2000, I I:433-9.

5. Chhabra S, Sonak M, Prem V, Sharma S: Gynaecological malignancies in a rural institute in India. J Obstet Gynaecol 2002, 22:426-9.

6. Gavarasana S, Kalasapudi RS, Rao TD, Thirumala S: Prevention of carcinoma of cervix with human papillomavirus vaccine. Indian / Cancer 2000, 37:57-66.

7. Koutsky LA, Ault KA, Wheeler CM, Brown DR, Barr E, Alvarez FB, Chiacchierini LM, Jansen KU: Proof of Principle Study InvestigatorsA controlled trial of a human papillomavirus type 16 vaccine. N Engl J Med 2002, 347:|645-5|

8. Harper DM, Franco EL, Wheeler C, Ferris DG, Jenkins D, Schuind A Zahaf T, Innis B, Naud P, Decarvalho NS, Roteli-Martins CM, Teixeira J, Blotter MM, Kom AP, Quint W, Dubin G: for the GlaxoSmithKline HPV Study Group. Efficacy of a Bivalent LI Virus-Like Particle Vaccine in Prevention of Infection With Human Papillomavirus Types 16 and 18 in Young Women: A Randomized Trial. Obstet Gynecol Surv 2005, 60: I7I- I73.

9. Munoz N, Bosch FX, Castellsague X, Diaz M, de Sanjose S, Hammouda D, Shah KV, Meijer C]: Against which human papillomavirus types shall we vaccinate and screen? The international perspective. Int J Cancer 2004, I I I:278-85.

10. Pagliusi SR, Teresa Aguado M: Efficacy and other milestones for human papillomavirus vaccine introduction. Vaccine 2004 23:569-578.

II. Sharma DC: HPV vaccine trial may take place in India. Lancet Oncol 2002, 3:649.

12. Franceschi S, Rajkumar T, Vaccarella S, Gajalakshmi V, Sharmila A, Snijders PJ, Munoz N, Meijer CJ, Herrero R: Human papillomavirus and risk factors for cervical cancer in Chennai, India: a case-control study. Int ] Cancer 2003, I07:127-33

13. Das BC, Sehgal A, Murthy NS, Gopalkrishna V, Sharma JK, Das DK, Singh V, Luthra UK: Human papillomavirus and cervical cancer in Indian women. Lancet 1989, 2:1271.

14. Franceschi S, Rajkumar R, Snijders PJ, Arslan A, Mahe C, Plummer M, Sankaranarayanan R, Cherian J, Meijer CJ, Weiderpass E: Papillomavirus infection in rural women in southern India. $\mathrm{Br} / \mathrm{Cancer}$ 2005, 92:601-6.

15. Sankaranarayanan R, Nene BM, Dinshaw KA, Mahe C, Jayant K, Shastri SS, Malvi SG, Chinoy R, Kelkar R, Budukh AM, Keskar V, Rajeshwarker R, Muwonge R, Kane S, Parkin DM, Chauhan MK, Desai S, Fontaniere B, Frappart L, Kothari A, Lucas E, Panse N, Osmanabad District Cervical Screening Study Group: A cluster randomized controlled trial of visual, cytology and human papillomavirus screening for cancer of the cervix in rural India. Int J Cancer 2005, I 16:617-23.

16. Preparation and ananlysis of DNA. Short protocols in molecular biology 3rd edition. Edited by: Ausubel et al. New York: Wiley; 1995.

17. Gravitt PE, Peyton CL, Alessi TQ, Wheeler CM, Coutlee F, Hildesheim A, Schiffman MH, Scott DR, Apple RJ: Improved amplification of genital human papillomaviruses. J Clin Microbiol 2000, 38:357-6I

18. Gravitt PE, Peyton CL, Apple RJ, Wheeler CM: Genotyping of 27 human papillomavirus types by using $L I$ consensus PCR products by a single-hybridization, reverse line blot detection method. I Clin Microbiol 1998, 36:3020-7.

19. Munoz N, Bosch FX, de Sanjose S, Herrero R, Castellsague X, Shah KV, Snijders PJ, Meijer C): International Agency for Research on Cancer Multicenter Cervical Cancer Study Group. Epidemiologic classification of human papillomavirus types associated with cervical cancer. N Engl J Med 2003, 348:5 1 8-27.
20. Bosch FX, Manos MM, Munoz N, Sherman M, Jansen AM, Peto J, Schiffman MH, Moreno V, Kurman R, Shah KV: Prevalence of human papillomavirus in cervical cancer: a worldwide perspective. International biological study on cervical cancer (IBSCC) Study Group. J Natl Cancer Inst 1995, 87:796-802.

21. Walboomers JM, Jacobs MV, Manos MM, Bosch FX, Kummer JA, Shah $\mathrm{KV}$, Snijders PJ, Peto J, Meijer C], Munoz N: Human papillomavirus is a necessary cause of invasive cervical cancer worldwide. J Pathol 1999, 189:12-9.

22. Munoz N: Human papillomavirus and cancer the epidemiological evidence. J Clin Virol 2000, 19:1-5.

23. [http://www.canceratlasindia.org]

24. Clifford GM, Smith JS, Plummer M, Munoz N, Franceschi S: Human papillomavirus types in invasive cervical cancer worldwide: a meta-analysis. Br J Cancer 2003, 88:63-73.

25. Schiffman M, Kjaer SK: Natural history of anogenital human Papillomavirus infection and neoplasia. I Natl Cancer Inst Monogr 2003, 3 I: | 4-9.

26. Sankaranarayanan R, Chatterji R, Shastri SS, Wesley RS, Basu P, Mahe C, Muwonge R, Seigneurin D, Somanathan T, Roy C, Kelkar R, Chinoy R, Dinshaw K, Mandal R, Amin G, Goswami S, Pal S, Patil S, Dhakad $\mathrm{N}$, Frappart L, Fontaniere B: Accuracy of human papillomavirus testing in primary screening of cervical neoplasia: results from a multicenter study in India. Int J Cancer 2004, I I 2:34 I-7.

27. Legood R, Gray AM, Mahe C, Wolstenholme J, Jayant K, Nene BM, Shastri SS, Malvi SG, Muwonge R, Budukh AM, Sankaranarayanan R: Screening for cervical cancer in India How much will it cost? A trial based analysis of the cost per case detected. Int J Cancer 2005, I | 7:98|-7.

\section{Pre-publication history}

The pre-publication history for this paper can be accessed here:

\section{http://www.biomedcentral.com/1471-2334/5/116/pre} pub
Publish with Biomed Central and every scientist can read your work free of charge

"BioMed Central will be the most significant development for disseminating the results of biomedical research in our lifetime. "

Sir Paul Nurse, Cancer Research UK

Your research papers will be:

- available free of charge to the entire biomedical community

- peer reviewed and published immediately upon acceptance

- cited in PubMed and archived on PubMed Central

- yours - you keep the copyright
BioMedcentral 